\title{
Potential of high-frequency ultrasounds to improve sludge anaerobic conversion and surfactants removal at different food/inoculum ratio
}

\author{
A. Gallipoli, A. Gianico, M.C. Gagliano, C.M. Braguglia* \\ Istituto di Ricerca sulle Acque-CNR, Area della Ricerca RM1, Via Salaria km. 29,300, 00015 Monterotondo, Roma, Italy
}

\section{H I G H L I G H T S}

- Novel application of high frequency ultrasounds as sludge pre-treatment is proposed.

- Effect of food/inoculum (F/I) ratio was assessed by batch anaerobic digestion tests.

- First order kinetic evidenced decreasing trend of hydrolysis rate by increasing F/I.

- Ultrasounds improved specific biogas production, particularly at low F/I.

- F/I affected the anionic surfactants removal and the homologues degradation pathway.

\section{A R T I C L E I N F O}

\section{Article history:}

Received 18 December 2013

Received in revised form 17 February 2014

Accepted 22 February 2014

Available online 3 March 2014

\section{Keywords:}

Anaerobic digestion

Biogas

High-frequency ultrasounds

Sludge pretreatment

Surfactants

\begin{abstract}
A B S T R A C T
High-frequency ultrasounds have recently gained interest as oxidative technique for sonochemical degradation of organic contaminants in water. In this study an innovative approach applying $200 \mathrm{kHz}$ ultrasounds to improve both sludge anaerobic biodegradability and decontamination is proposed. Digestion tests were performed on batch reactors fed either with untreated or sonicated sludge, at different food/inoculum (F/I) ratio, in the range 0.3-0.9. First order kinetic highlighted a decreasing trend of the hydrolysis rate by increasing F/I, both for untreated and sonicated sludge. Positive effect of ultrasounds on specific biogas production was evident, but the conversion rate for pretreated sludge was strongly affected by F/I, and decreased by increasing F/I. Anionic surfactants anaerobic removal occurred in all tests, but the effect of ultrasounds was significant only at $F / I=0.3$. By pretreating sludge with high frequency ultrasounds, low F/I was the ideal ratio improving both sludge anaerobic digestion and decontamination.
\end{abstract}

๑ 2014 Elsevier Ltd. All rights reserved.

\section{Introduction}

Biosolids land application is nowadays considered the best environmental and economic option to reduce the sludge volume requiring disposal on landfill. In order to produce suitable biosolids, advanced sludge treatments have to (a) reduce sludge volume and mass, (b) remove putrescible and degradable materials, avoiding odour generation, and (c) eliminate pathogens. Among treatment options, anaerobic digestion represents a widely applied biological technology for stabilizing sludge, also because the biogas produced during the digestion process is a clean and environmentally friendly fuel.

One of the crucial factors affecting anaerobic digestion of organic solids is the selection of the food/inoculum ratio as well as the

\footnotetext{
* Corresponding author. Tel.: +39 0690672798; fax: +390690672787.

E-mail address: braguglia@irsa.cnr.it (C.M. Braguglia).
}

assessment of anaerobic biodegradability of sludge (Neves et al., 2004).

The food to inoculum ratio $(\mathrm{F} / \mathrm{I})$ is expressed as the amount of feedstock volatile solids (VS) added per the amount of inoculum VS (Liu et al., 2009). Although this ratio could theoretically affect only the kinetics, and not the ultimate methane yield (which depends only on the organic matter content), it is widely reported that too high F/I may be toxic while too low F/I could prevent enzyme induction for biodegradation (Neves et al., 2004; Prashanth et al., 2006). According to Neves et al. (2004) a substrate to inoculum $(S / I)$ ratio ranging between $0.5 \mathrm{gVS} / \mathrm{gVS}$ and $2.3 \mathrm{gVS} / \mathrm{gVS}$ could prevent volatile fatty acids accumulation and instability of the anaerobic process. Further studies (Liu et al., 2009) showed that the biogas yield was inversely related to the $S / I$ ratio in the range 1.6-5.0.

Nevertheless, the biogas yields for the anaerobic digestion of solid wastes, as sewage sludge, are generally low because of the 
biological hydrolysis, considered the rate-limiting step of the whole process due to the particulate nature of this feedstock (Pavlostathis and Gosset, 1986; Shimizu et al., 1993; Tomei et al., 2008).

During the hydrolysis phase, several processes take place, namely the disintegration of sludge matrix, the solubilisation of particulate matter and the biological decomposition of extracellular polymeric substances, primarily responsible of sludge floc structure and integrity. For this reason, in recent years, a great deal of attention has been focused on mechanical, thermal or chemical pre-treatments of waste activated sludge, which facilitate breakage of flocs, and cell walls, enhancing the hydrolysis of sludge volatile solids (Braguglia et al., 2011; Carlsson et al., 2012; Khanal et al., 2007; Pilli et al., 2011). Among mechanical methods, ultrasounds at low frequency (around $20-24 \mathrm{kHz}$ ) has been extensively used as sludge pretreatment for improving anaerobic digestion performances, both at lab scale (Bougrier et al., 2005; Perez-Elvira et al., 2009; Tiehm et al., 2001) and full-scale applications (Neis et al., 2008; Xie et al., 2007).

Furthermore, it was recently demonstrated by Gallipoli and Braguglia (2012) that also higher ultrasounds frequency, as $200 \mathrm{kHz}$, caused floc matrix disintegration and organic matter solubilisation. At the same time, high frequency ultrasounds gained interest for wastewater decontamination because of the oxidative degradation of organic contaminants by means of $\mathrm{OH}$ radicals, generated from water sonolysis. However, despite the high amount of persistent and ubiquitary organic contaminants present in sewage sludge, the application of ultrasounds to degrade pollutants via sonolysis before anaerobic degradation, was never reported in literature so far.

Among the organic contaminants accumulating into sludge, an important group is constituted by linear alkylbenzene sulphonates (LAS), a class of anionic surfactants, components of synthetic detergent formulations for both domestic and industrial purposes. Many studies about the biodegradation of LAS have demonstrated that anionic surfactants are readily biodegradable under aerobic conditions, while studies on LAS removal in anaerobic conditions showed a negligible surfactants biodegradation. In fact, according to the findings of Berna et al. (1989), high concentrations of LAS (5-10 g LAS $/ \mathrm{kg}$ ) have been found in anaerobically digested sludge. For this reason recent research was addressed to improve LAS anaerobic biodegradation potential (Angelidaki et al., 2004; Mogensen et al., 2003) since LAS are strongly adsorbed onto sludge.

On the basis of these considerations, main objective of this work was to assess the potential of high frequency ultrasounds as sludge pre-treatment, in order to combine the enhancement of the anaerobic sludge digestibility with the sludge decontamination via pollutants oxidation. The ultrasounds potential was evaluated by performing anaerobic digestion tests carried out with untreated and sonicated sludge, by monitoring organics solubilisation and removal, biogas production and linear alkyl benzenes sulphonates (LAS) fate during the anaerobic process.

The impact of the initial food/inoculum ratio on the digestion performances was assessed, too.

\section{Methods}

\subsection{Sludge}

The anaerobic digestion experiments were performed on waste activated sludge (WAS), untreated and sonicated at $200 \mathrm{kHz}$. The sludge was obtained from the municipal "Roma Nord" wastewater treatment plant, serving about 700,000 P.E. The treatment plant is a conventional one including screening, primary clarification and secondary treatment by activated sludge, operating with a quite high sludge age (20 d).
Secondary sludge was sampled from the recycle stream before secondary clarifier and gravity thickened for $24 \mathrm{~h}$ at $4^{\circ} \mathrm{C}$ up to total solids concentration of 21-24 g/L, before feeding the bench scale anaerobic reactors.

The anaerobic inoculum was sampled from the full scale digester of the plant fed with mixed sludge. Microbial composition analysis of the inoculum was carried out with Fluorescence in situ Hybridization (FISH), using specific probes for Bacteria (EUB338mix) and Archaea (arc915) domains. FISH procedure is reported elsewhere (Braguglia et al., 2012). Bacteria relative abundances was $40 \%$ out of total cells (estimated with DAPI staining), while archaeal population was 5\% out of total cells. Two predominant archaeal morphotypes were identified: long Methanosaeta filaments, and cocci organised in sarcine, identified as Methanosarcina spp.

The principal characteristics of secondary raw and sonicated sludge and inoculum used in the digestion tests are summarised in Table 1.

Total and volatile solids (TS and VS) were determined according to standard methods (APHA, 1998). To analyse the soluble phase, the particulate sludge matter was removed by centrifugation (10 min at $4000 \mathrm{rpm}$ ) and resulting centrate was filtrated through $0.45 \mu \mathrm{m}$ pore size membrane filters. Soluble COD (Chemical Oxygen Demand), measured in duplicates, was determined by photometric determination of chromate consumption by the organic compounds, subsequent to digestion in concentrated sulphuric acid solution for $2 \mathrm{~h}$ at $148{ }^{\circ} \mathrm{C}$ by means of COD Cell Test by Spectroquant Merck (EPA method 410.4).

\subsection{Ultrasound pretreatment}

The ultrasound apparatus is constituted of flat-plate type stainless-steel ultrasonic reactor (model USW 51-051) supplied by Elac Nautik Incorporated, Kiel, Germany, operating at $200 \mathrm{kHz}$ and an average power of $90-100 \mathrm{~W}$. Both frequency and power were adjusted with the AG 1006 LF generator/amplifier (T\&C power Conversion), connected to the transducer. The delivered ultrasound power, measured by calorimetric method, was in the range $10-20 \mathrm{~W}$, and the average energy efficiency of this transducer was therefore $\sim 15 \%$. The plate type transducer is made up of a piezo-ceramic element and the active acoustic vibration surface area is approximately $25 \mathrm{~cm}^{2}$. The reactions were performed in a $500 \mathrm{~mL}$ glass reaction chamber, double-walled (cooling jacket) and covered. Ultrasonic irradiation at $200 \mathrm{kHz}$ was performed for $40 \mathrm{~min}$ on $400 \mathrm{~mL}$ of real waste activated sludge. The ultrasound treatment was carried out immediately before starting the anaerobic digestion experiments.

The effectiveness of the disintegration pretreatment was evaluated by measuring the "disintegration degree" ( $\left.\mathrm{DD}_{\mathrm{COD}} \%\right)$, namely the ratio of the soluble COD increase due to pretreatment to the maximum possible soluble COD increase (Braguglia et al., 2006). The degree of disintegration is dependent on the specific energy supplied $\left(E_{\text {spec }}\right)$ which can be calculated by the Eq. (1):

$E_{\text {spec }}=\frac{P \times t_{t}}{V \times T S}$

where $P$ is the power of the ultrasonic processor, $t_{t}$ the sonication time, $V$ the sludge treated volume and TS the sludge total solids

Table 1

Feed sludge and inoculum characterization.

\begin{tabular}{llll}
\hline & Raw sludge & Sonicated sludge & Inoculum \\
\hline TS $(\mathrm{g} / \mathrm{L})$ & $21.3-24.1$ & $21.8-23.2$ & $20.9-31.7$ \\
VS $(\mathrm{g} / \mathrm{L})$ & $12.5-14.4$ & $13-14.4$ & $11.9-20.2$ \\
VS/TS (\%) & $57-65$ & $58-66$ & $55-64$ \\
Soluble COD (mg/L) & $15-50$ & $1125-1560$ & $271-373$ \\
LAS $(\mathrm{mg} / \mathrm{kg} \mathrm{d} \mathrm{m})$ & $50-60$ & $40-70$ & $400-670$ \\
\hline
\end{tabular}


content. The specific energy supplied for sludge ultrasound pretreatment was in the range $20,000-25,000 \mathrm{~kJ} / \mathrm{kgTS}$, and the disintegration degree was maintained constant around $7 \%$ in all tests.

\subsection{Batch anaerobic digestion tests}

Experiments were carried out on bench scale anaerobic reactors of $0.4 \mathrm{~L}$ which were operated in batch mode, immersed in a temperature controlled, agitated water bath at $37^{\circ} \mathrm{C}$. The reactors were fed with a mixture of anaerobic biomass (as inoculum) and secondary sludge (as feed), either untreated or disintegrated. F/I was calculated with the Eq. (2):

$\frac{\mathrm{F}}{\mathrm{I}}=\frac{V_{\text {sludge }} \times V S_{\text {sludge }}}{\left(V_{\text {tot }}-V_{\text {sludge }}\right) \times V S_{\text {inoculum }}}$

To assess the biogas production due to the sole inoculum, the substrate volume was replaced by distilled water in the "blank" reactor. The average inoculum specific biogas production was $0.035 \pm 0.003 \mathrm{~L} / \mathrm{gVS}_{\text {inoc }}$.

The produced biogas was collected in calibrated $1 \mathrm{~L}$ eudiometer tube placed on the digestion bottle via a ground-glass connection. The tube has a glass hose-coupling from which a sufficiently long hose connection leads a levelling flask. The upper end of the eudiometer tube is fitted with a conical stopcock for adjusting the zero point. The liquid contained in the tube and in the levelling flask was $\mathrm{NaCl}$ at $\mathrm{pH} 3$ to avoid $\mathrm{CO}_{2}$ losses by carbonate formation. The biogas was read daily. At regular time intervals $(2,6$ and 20 days), one digestion reactor containing untreated and one containing sonicated sludge were stopped and sludge analyses were performed, while the inoculum was analysed only at the beginning and the end of the test. The digestion tests were performed at different $F / I$ ratio $(0.3,0.6$ and 0.9$)$ to investigate the impact of the anaerobic biomass content during the process, too.

\subsection{Kinetic study}

The volatile solids measured during the digestion tests were used for kinetic calculations. The hydrolysis kinetics were assumed to follow a first-order kinetic Eq. (3):

$\frac{d X s}{d t}=-k_{x} X s$

where $k_{x}$ is the hydrolysis constant $\left(\mathrm{d}^{-1}\right), t$ is time and $X_{S}$ is the anaerobically degradable fraction of activated sludge. Total volatile solids of activated sludge $\left(X_{T}\right)$ are constituted of degradable fraction $\left(X_{S}\right)$ and a non-degradable fraction $\left(X_{I}\right)$, namely inert material originated by endogenous biomass decay process. The active biomass involved in the hydrolysis process is assumed in first approximation equal to the VS content of the inoculum. The concentration of "digestible" substrate can be expressed as $X_{S}=f_{X} X_{T}$, while $X_{I}$ is $\left(1-f_{X}\right) X_{T}$, where $f_{X}$ is the anaerobically degradable fraction. The ratio $f_{X}=X_{S} / X_{T}$ is reported in literature in the range 0.3-0.4 (Engelhart, 2002) depending on the operating conditions of the treatment plant: in these experiments, $f_{x}$ was assumed to have a low value $(0.35)$ because the full scale plant is operated at high sludge retention time (SRT $=20 \mathrm{~d}$ ) so a quite high non biodegradable fraction is expected in the produced sludge. Integrating the previous equation, it results Eq. (4):

$\frac{X_{S f}}{X_{S 0}}=e^{-k_{x} t_{f}}$

where the subscript 0 and $f$ represent the initial and final time, respectively. Expressing $X_{S O}$ as $f_{X} X_{T 0}$, it can be written Eq. (5):

$X_{S f}=f_{x} X_{T 0} e^{-k_{x} t_{f}}$
The VS mass balance referring to the whole digestion time at the final VS concentration $X_{T f}$ is expressed by Eq. (6):

$X_{\text {Tf }}=X_{T 0}\left\lfloor 1-f_{X}\left(1-e^{-k_{x} t_{f}}\right)\right\rfloor$

The VS degradation efficiency is defined as $\eta=1-\left(X_{t f} \mid X_{t 0}\right)$, hence Eq. (7):

$\eta=f_{x}\left(1-e^{-k_{x} t_{f}}\right)$

or in the linearized form Eq. (8):

$\ln \left(1-\frac{\eta_{x}}{f_{x}}\right)=-k_{x} \times t_{f}$

Plotting $\ln \left(1-\eta_{x} / f_{x}\right)$ versus digestion time, the slope of the straight line represents the hydrolysis constant $k_{x}$, while $R^{2}$ of each straight line confirms the hypothesis of a first-order kinetic.

\subsection{LAS extraction and analysis}

The experimental procedure for LAS extraction and analysis was carried out following CEN standard method for solid samples (CEN/ TS 16189, 2010). Surfactants extraction was done in duplicate. The separation of the four different LAS homologues (C10, C11, C12, C13) was performed with a Dionex HPLC equipped with a lowpressure gradient pump with integrated vacuum degasser, autosampler and an Acclaim Surfactant (Dionex) column $5 \mu \mathrm{m} 120 \AA$ $(2.1 \times 150 \mathrm{~mm})$. The isocratic mobile phase was acetonitrile/ $100 \mathrm{mM}$ ammonium acetate $(65: 35 \mathrm{v} / \mathrm{v})$ flowing at $0.2 \mathrm{~mL} \mathrm{~min}^{-1}$. LAS determination was obtained with a single quadrupole mass detector PE Sciex API 165 with a Turbo IonSpray source, operating in negative ionisation. LAS identification and quantification were performed in full scan acquisition and in selected ion monitoring (SIM) mode, respectively. The 4-octylbenzenesulphonate (C8-LAS) was added to the sludge sample before extraction, as internal standard to correct the losses during the analytical procedure. Six-point calibration curves were generated for each LAS homologues by injecting pooled solutions prepared from the standard mixtures. The linearity range for the LAS mixtures was $0.1-100 \mathrm{mg} / \mathrm{L}$ total LAS. Quantitative analysis was done by calculating the ratios between the peak area of each homologue and the peak area of the internal standard. The same procedure was used to plot calibration curves from the standard solutions.

\subsection{Proteins and carbohydrates determination}

Sludge aliquots were filtered through glass filters with $1.2 \mu \mathrm{m}$ pores (GF/C Whatman); the supernatant was used for protein and carbohydrates determination. Protein content was calculated by means of the modified Lowry Kit for Protein Determination, Sigma-Aldrich P 5656. Carbohydrates determination was based on a colorimetric method proposed by Dubois et al. (1956) and modified by Taylor (1994). The calibration curve was constructed using fructose instead of glucose and the absorbance of standard and samples were measured at $488 \mathrm{~nm}$. The use of fructose allowed completing the dehydration reactions and the formation of chromogen, avoiding the drawback of the glucose standard assay of the variable absorbance response to different sugars (Taylor, 1994).

\subsection{Specific surface charge determination}

Sludge samples are centrifuged at $5000 \mathrm{rpm}$ for $10 \mathrm{~min}$, the centrate was then filtered through a $1.2 \mu \mathrm{m}$ filter and titrated in the PCD (Particle Charge Detector) to determine the quantity of charge related to the colloidal particles. The charge density determinations were performed by a Particle Charge Detector PCD02 (Mütek $\mathrm{GmbH}$, Herrsching). The PCD operates on the principle of the 
"streaming current detector". Since the streaming current is proportional to the electric charge of the colloids, it may provide an indication of charge-related particle destabilization in a manner similar to zeta potential. The charge amount of the sample was quantitatively measured by polyelectrolyte titration, a titrant (organic polyelectrolyte) of opposite charge to the sample was added until the latter reached the point of zero charge. The original charge amount was calculated from the titrant consumption.

\section{Results and discussion}

The potential of sludge ultrasonic pretreatment at $200 \mathrm{kHz}$ was assessed in terms of (1) sludge solubilisation (as release of proteins, polysaccharides, and organic substances), (2) volatile solids removal and kinetics, (3) biogas production and (4) LAS fate during batch digestion tests carried out with untreated and sonicated sludge at different $\mathrm{F} / \mathrm{I}(0.3,0.6$ and 0.9$)$.

The sludge disintegration potential of ultrasounds treatment was evidenced by the soluble COD increase in the pretreated sludge samples at the beginning of the digestion tests (Table 1). Because of the high-frequency sound waves the breakage of the floc matrix occurred, improving the release of the extracellular organic matter into the liquid phase (Gallipoli and Braguglia, 2012).

\subsection{Anaerobic solubilization of organic substance}

In the pretreated sludge digestion tests, in spite of the high initial soluble COD in the reactors, due to mechanical pre-disintegration, further hydrolysis of particulate material occurred with soluble COD accumulation (Fig. 1), in particular at $F / I=0.9$. However, significant COD removals have been observed for the digestion tests of sonicated sludge, thus reaching comparable values as those obtained with anaerobic digestion of untreated sludge. The efficiencies of soluble COD removal at the end of the process were $13 \%, 53 \%$ and $33 \%$ for the digestion at $\mathrm{F} / \mathrm{I}=0.3,0.6$ and 0.9 , respectively.

The soluble COD pattern during the untreated sludge digestion was independent on the F/I. During the first days of the process, soluble COD increased due to the release of organics, accumulating in the reactor (Fig. 1). For the test at $\mathrm{F} / \mathrm{I}=0.9$, with higher substrate fraction, the hydrolysis phase resulted rapid and intense, reaching high soluble COD concentration ( $1439 \mathrm{mg} / \mathrm{L}$ ) just after $48 \mathrm{~h}$ of digestion, progressively removed during the digestion up to a concentration of $460 \mathrm{mg} / \mathrm{L}$.

Soluble COD trend during anaerobic digestion tests was closely related to the fate of soluble substances in the digesters. The extracellular polymeric substances (EPS), mainly constituted of proteins and carbohydrates, represent a considerable fraction of the organic material in waste activated sludge which can be released into the liquid phase after the ultrasound pretreatment. EPS together with divalent cations are considered the most important parameters governing WAS hydrolysis and determining floc structure, integrity and strength. Moreover, EPS are the main responsible of the negative surface charge of sludge flocs, at neutral $\mathrm{pH}$, affecting consequently sludge dewaterability (Novak et al., 2003).

Proteins concentration was always noticeably higher than carbohydrates concentration, for both untreated and sonicated digestion tests (Table 2), as confirmed also by Novak et al. (2003), affirming that for anaerobic systems, the protein concentration is 3-5 times greater. The dominance of protein in sludge could be due to the presence of a large quantity of exoenzymes inside the flocs matrix.

The increase of proteins and carbohydrates in the supernatant for both untreated and sonicated sludge in the first days of digestion confirmed the initial particulate hydrolysis, independent of sonication. The accumulation, as just discussed for soluble COD, was more evident in the test at F/I 0.9. After the first phase, the removal of proteins occurred progressively up to the end, while polysaccharides were removed up to the 6th day and then the soluble concentration remained almost constant. Novak et al. (2003) evidenced that during anaerobic digestion, the release of proteins was relatively rapid, while polysaccharides were released more slowly.

Despite the high initial bio-polymers concentration due to the ultrasonic pretreatment (that act as "mechanical" hydrolysis step) at the end of the sonicated sludge digestion the concentration of proteins and carbohydrates was comparable with the one present in the untreated sludge digesters.

Moreover, because of the high content of colloidal charged particles deriving from sludge disintegration due to ultrasounds, the surface charge at the start up phase in the digesters fed with pretreated sludge was always higher with respect to those fed with untreated sludge. The hydrolysis phase of digestion was confirmed by the initial increase of specific surface charge both for untreated and sonicated sludge, because of fine particles generation. In the case of the high and medium-inoculum tests (F/I 0.3 and 0.6 ) a continuous increasing trend of specific surface charge was observed independently of the sonication, reaching very high values at the end of digestion, in particular at $\mathrm{F} / \mathrm{I}=0.3$. This low $\mathrm{F} / \mathrm{I}$ ratio probably could not assure sufficient substrate for the anaerobic bacteria growth during the whole digestion process. In this situation, bacteria recovered the required energy from the cell protoplasm autoxidation by means of endogenous respiration, leading to an increase of fine particles and therefore of the specific charge in the supernatant.

On the contrary, at high substrate fraction (as $F / I=0.9$ ) surface charge decreased slightly because of the removal of colloidal charged polymers as proteins and carbohydrates. The intense removal of fines in the digested sludge, strictly related to the decrease of the particles surface charge, could improve final sludge dewaterability (Novak et al., 2003).
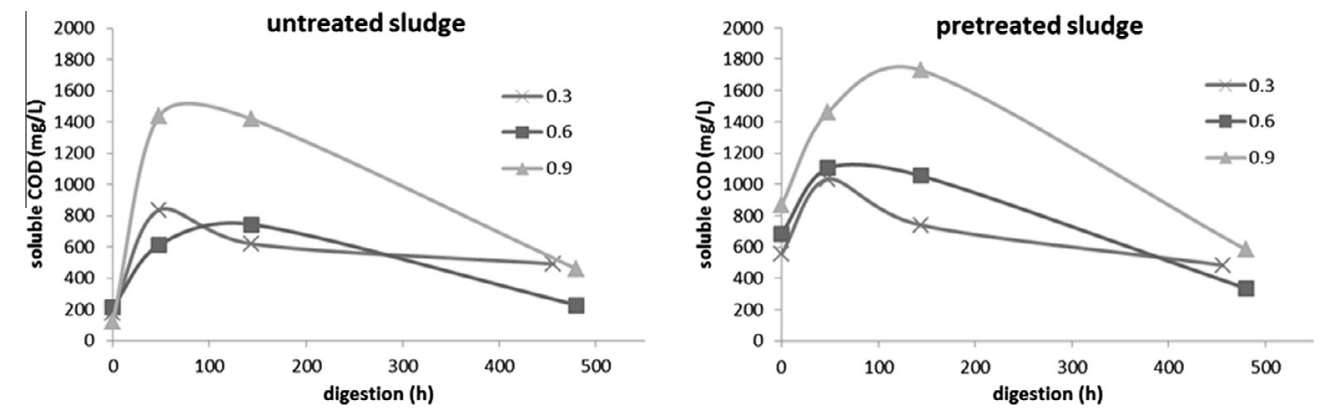

Fig. 1. Soluble COD trends in the digestion tests. 
Table 2

Soluble EPS content $(\mathrm{mg} / \mathrm{L})$ and specific surface charge $(\mathrm{C} / \mathrm{L})$ in the digestion tests.

\begin{tabular}{|c|c|c|c|c|c|c|c|c|c|}
\hline \multicolumn{4}{|c|}{ F/I 0.3} & \multicolumn{3}{|l|}{ F/I 0.6} & \multicolumn{3}{|l|}{ F/I 0.9} \\
\hline$h$ & Proteins & Carbohydrates & Specific surface charge & Proteins & Carbohydrates & Specific surface charge & Proteins & Carbohydrates & Specific surface charge \\
\hline \multicolumn{10}{|c|}{ Untreated sludge } \\
\hline 0 & 143 & 62 & 1.0 & 122 & 35 & 1.4 & 122 & 33 & 2.3 \\
\hline 48 & 458 & 168 & n.d. & 347 & 159 & 4.6 & 501 & 167 & 6.6 \\
\hline 144 & 387 & 121 & 5.3 & 409 & 110 & 5.0 & 594 & 139 & 6.3 \\
\hline 480 & 302 & 190 & 19.9 & 177 & 137 & 7.4 & 426 & 132 & 4.3 \\
\hline \multicolumn{10}{|c|}{ Pretreated sludge } \\
\hline 0 & 235 & 206 & 1.0 & 189 & 141 & 2.6 & 296 & 128 & 5.8 \\
\hline 48 & 634 & 252 & n.d. & 354 & 244 & 4.6 & 485 & 183 & 7.1 \\
\hline 144 & 389 & 148 & 5.9 & 424 & 123 & 4.8 & 357 & 148 & 6.4 \\
\hline 480 & 325 & 137 & 13.8 & 210 & 163 & 7.9 & 337 & 137 & 5.5 \\
\hline
\end{tabular}

\subsection{Anaerobic volatile solids degradation}

The volatile solids removal efficiencies for both untreated and sonicated sludge (Table 3) were in the range $23-48 \%$ typical for waste activated sludge digestion (Bolzonella et al., 2005; Braguglia et al., 2011) and decreased by increasing the F/I ratio, i.e. by lowering the inoculum fraction of the solids in the digester. At the same time, the positive effect of ultrasound pretreatment was more evident by increasing $\mathrm{F} / \mathrm{I}$, and the improvement due to sonication was $+13 \%$ and $+29 \%$ for the tests at $F / I=0.6$ and 0.9 , respectively. No effect of sonication was evidenced at $F / I=0.3$. This result highlighted the importance of anaerobic biomass fraction at the digestion start up, in particular when substrate is rich in soluble organics due to sonication pretreatment.

The digestion process kinetics are strictly dependent on the hydrolysis rate of particulate substrate, because hydrolysis is the rate-limiting step of the whole digestion process (Pavlostathis and Gossett, 1986). According to Vavilin et al. (1996), the real difficulty in sludge anaerobic digestion is to discern the active biomass (assumed here equal to the VS of the inoculum) from the sludge volatile solids representing the substrate (i.e. waste activated sludge, untreated or sonicated). It was therefore hypothesized that the total VS in the sludge to be digested are constituted by a degradable fraction and by a non-degradable fraction originated by the endogenous biomass decay process.

Fig. 2 shows the hydrolysis constant $\left(k_{h}\right)$ for the untreated and pretreated sludge at the investigated $\mathrm{F} / \mathrm{I}$ ratios.

The $k_{h}$ values for the untreated WAS digestion process ranged between $0.09 \mathrm{~d}^{-1}$ and $0.55 \mathrm{~d}^{-1}$, and resulted consistent with other authors findings (Tomei et al., 2008; Zhang et al., 2010).

The high solids removal observed for the digestion at $\mathrm{F} / \mathrm{I}=0.3$ (Table 3) was confirmed by the very high hydrolysis rates of $0.55 \mathrm{~d}^{-1}$ and $0.34 \mathrm{~d}^{-1}$ for untreated and sonicated sludge, respectively, attributed to the endogenous respiration of the anaerobic bacteria due to the low amount of available external substrate.

The hydrolysis rate showed a decreasing trend by increasing the $\mathrm{F} / \mathrm{I}$ ratio, both for untreated and pretreated sludge digestion. This behaviour could depend on the excess of substrate with respect to the available hydrolytic biomass at high F/I ratio, thus leading to the hydrolysis rate reduction due to mass-transfer limitations, as reported also by other authors (Gianico et al., 2013; Raposo et al., 2009; Tomei et al., 2008). The positive effect due to

Table 3

Volatile solids removals (\%).

\begin{tabular}{lll}
\hline F/I & Untreated & Pretreated \\
\hline 0.3 & $48 \pm 3$ & $41 \pm 3$ \\
0.6 & $31 \pm 1.5$ & $35 \pm 2$ \\
0.9 & $24 \pm 1$ & $31 \pm 1.5$ \\
\hline
\end{tabular}

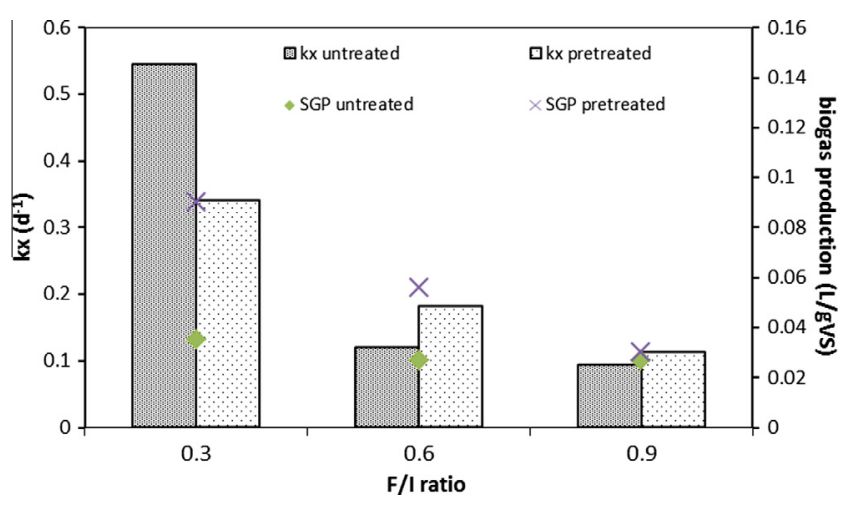

Fig. 2. Hydrolysis constant $k_{x}$ and specific biogas production vs F/I ratio.

pretreatment was observed for the medium (+54\%) and low inoculum fraction test $(+21 \%)$.

It is interesting to note that the estimated hydrolysis constants for pretreated sludge, sonicated at the "innovative" high frequency of $200 \mathrm{kHz}$, fall within the typical range for $20 \mathrm{kHz}$ sonicated sludge (Pavlostathis and Gosset, 1986; Tomei et al., 2008).

\subsection{Anaerobic biogas production}

Volatile solids degradation is directly related to biogas production during the anaerobic digestion process, as the high fraction of the removed VS are generally converted into biogas. The biogas production due to biomass decay and to the possible presence of residual substrate in the inoculum was subtracted by performing blank control tests (Angelidaki et al., 2009).

Fig. 2 shows the specific biogas production (SGP, expressed as $\left.\mathrm{L} / \mathrm{gVS}_{\text {substrate,fed }}\right)$ for untreated and pretreated sludge at the investigated $\mathrm{F} / \mathrm{I}$ ratios. The positive effect of the ultrasound pretreatment was observed for all the three tests, but the conversion rate for sonicated sludge was strongly affected by the F/I, and decreased by increasing $\mathrm{F} / \mathrm{I}$, while for the untreated sludge remained constant around $0.030 \pm 0.005$ independent on the F/I. The high soluble organics due to sonication affected significantly the conversion rate, in particular when the inoculum fraction was not enough (i.e. high F/I) to degrade the soluble organics of the feed.

The net cumulative biogas production obtained from untreated and pretreated sludge digestion at different $\mathrm{F} / \mathrm{I}$ ratio is shown in Fig. 3. As expected, the highest biogas production due to untreated sludge digestion was obtained working at $\mathrm{F} / \mathrm{I}=0.9$ because of the higher VS amount fed to the reactors. Different trend was observed for sonicated sludge digestion, because at F/I 0.9 the biogas production was noticeably lower with respect to the other ones. A kinetic decoupling between hydrolysis and methanogenesis may be 

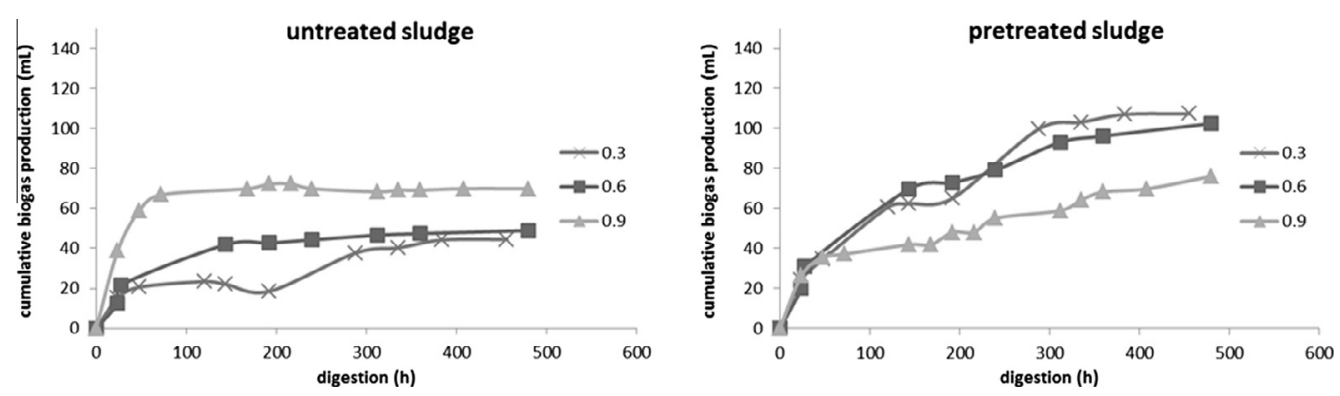

Fig. 3. Cumulative biogas production of untreated and pretreated sludge digestion at different $\mathrm{F} / \mathrm{I}$ ratio.

Table 4

LAS anaerobic degradation (\%).

\begin{tabular}{llc}
\hline F/I & Untreated mixture & Sonicated mixture \\
\hline 0.3 & $38 \pm 4$ & $49 \pm 5$ \\
0.6 & $26 \pm 3$ & $8 \pm 1.5$ \\
0.9 & $46 \pm 6$ & $41 \pm 5$ \\
\hline
\end{tabular}

hypothesized for the slowdown of the sonicated sludge at high $\mathrm{F} / \mathrm{I}$. This could be probably due to the accumulation of soluble organic substances, discussed in Section 3.1, which negatively affect the biogas production.

While the gain in biogas due to ultrasounds was very high operating at $\mathrm{F} / \mathrm{I}=0.3$ and 0.6 (Fig. 3 ), during the low inoculum test $(\mathrm{F} / \mathrm{I}=0.9)$ the biogas production of the untreated sludge was always higher compared to the pretreated one, and only at the end of the experiment the biogas production of pretreated sludge overtook the production of the untreated, with a final biogas gain of $+9 \%$.

\subsection{Anaerobic LAS degradation}

LAS degradation in batch anaerobic conditions occurred, either with untreated or ultrasounds pretreated sludge, but no linear relationship with the amount of substrate available for the anaerobic biomass in the reactors was observed (Table 4). The LAS degradation during the blank test was around $23-28 \%$.

Fig. 4 showed the LAS content in the reactors of both untreated and pretreated mixtures during the anaerobic digestion experiments, for all $\mathrm{F} / \mathrm{I}$ tested.

As regards the untreated sludge digestion, a remarkable removal of surfactants was observed in all tests, while the extent of LAS degradation in the pretreated sludge digestion was quite variable. Nevertheless, during the high $(F / I=0.3)$ and low inoculum test $(F / I=0.9)$ high surfactants removal was observed $(38-50 \%)$ and at low $\mathrm{F} / \mathrm{I}$ the effect of ultrasounds on LAS degradation improvement was statistically significant. In the case of $F / I=0.6$ test the removal was noticeably lower and for untreated sludge seemed ascribable only to the LAS content of the inoculum. The degradation pathway in the case of $\mathrm{F} / \mathrm{I}=0.9$ seemed completely different, both for untreated and sonicated sludge, with respect to the other two tests. In fact, in the first 6 days of digestion, a significant increase of the surfactants content was observed, probably due to the extraction of "aged" LAS by means of bacterial hydrolysis and floc disintegration. Similar results were reported in literature by monitoring other hydrophobic organic pollutants during digestion (Trably et al., 2003).

The marked effect of ultrasounds on LAS degradation at low F/I could probably be attributed to the high "food" dilution avoiding inoculum overload, in particular by feeding sonicated sludge rich of released bioavailable material. As highlighted for VS degradation, the kinetics at low F/I was noticeably higher with respect to the other investigated ratios, explaining the high removal of LAS from sludge. Evidently, the low F/I guarantee optimal conditions for surfactants degradation by means of the anaerobic biomass contained in the inoculum.

The degradation pattern of each LAS homologue was monitored during the digestion tests (Fig. 5). Among the homologues, LASC10 seemed more efficiently removed up to the end of the digestion process and the removal ranged from $16 \%$ to $48 \%$. A possible explanation of this phenomenon is that, since LAS-C10 is the less hydrophobic homologue, its concentration in the liquid phase overlying sludge is higher than the longer homologues, resulting the more available fraction for the anaerobic bacteria consortia (García et al., 2005). In fact, biodegradation of adsorbed organic contaminants can be a function of the mass transfer rates (from adsorbed to the aqueous phase) rather than the biodegradation rates (Bouchez et al., 1995). However, the extent of C10 biodegradation is comparable with the removal of the other LAS homologues; as a consequence, LAS homologues distribution (C10:C11:C12:C13 = 5:24:34:37) in the digested sludge were comparable with the ones of the secondary sludge used as substrate.

Differences in the homologue degradation trends were observed, depending on the food/inoculum ratio. Digesting at $\mathrm{F} / \mathrm{I}=0.3$ and 0.6 , the homologues degradation was progressive
LAS anaerobic degradation - untreated sludge

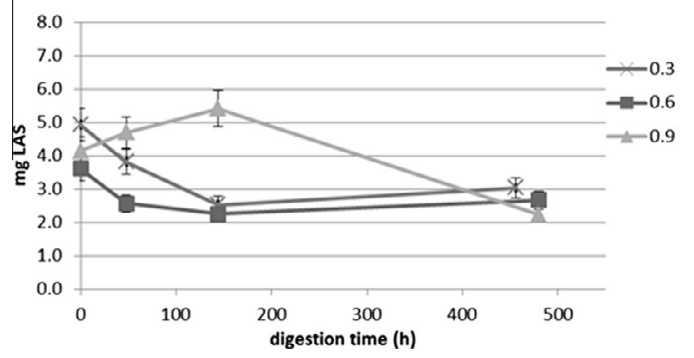

LAS anaerobic degradation - pretreated sludge

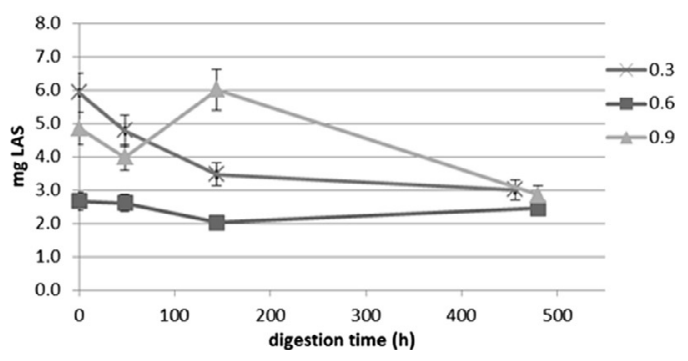

Fig. 4. LAS anaerobic degradation pattern. 
LAS-C10 pattern during anaerobic digestion

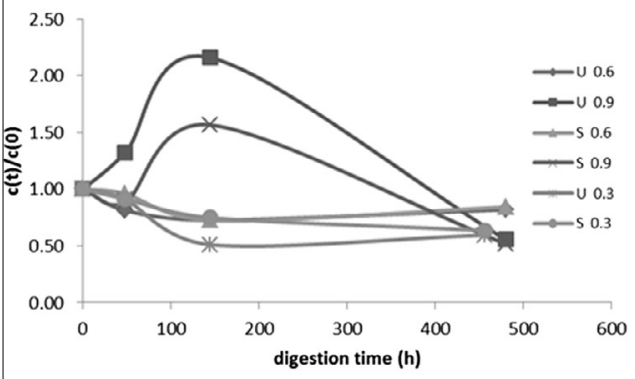

LAS-C12 pattern during anaerobic digestion

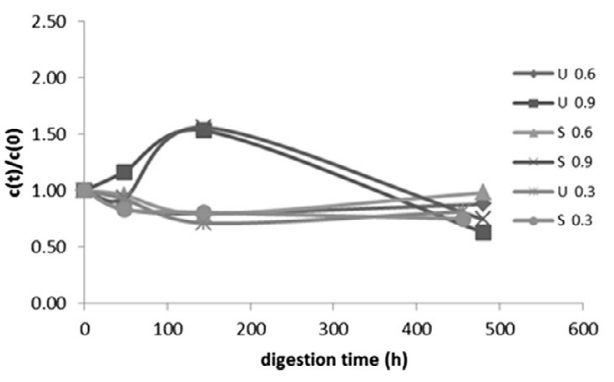

LAS-C11 pattern during anaerobic digestion

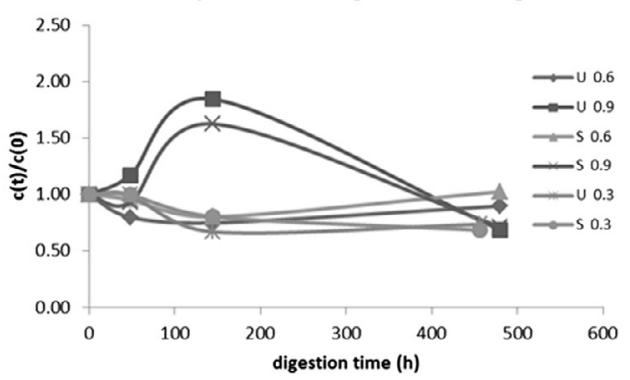

LAS-C13 pattern during anaerobic digestion

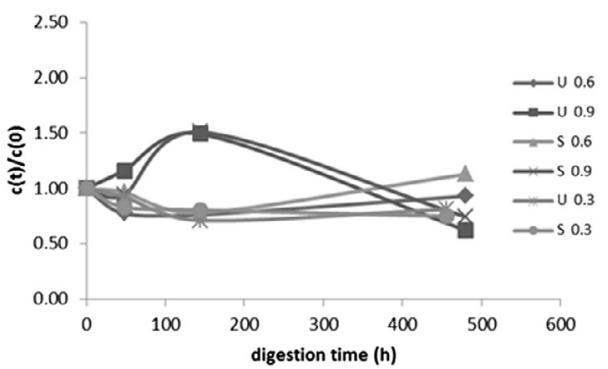

Fig. 5. LAS homologues degradation pattern.

during the first 6 days. Nevertheless, at the end of the $F / I=0.6$ digestion test the concentration was slight higher with respect to the previous one probably because of the release of the "aged" LAS, extracted during the digestion and not removed. Only in the case of pretreated sludge digestion at F/I 0.3, the LAS removal continued until the end of the test. This could be probably ascribable to the high amount of inoculum in the reactor and to the more disintegrated sludge matrix as a consequence of ultrasound pretreatment. Moreover, during digestion at $F / I=0.9$, the increase of the LAS-homologues concentration evidenced a significant accumulation due to the "extraction" of these compounds from the sludge matrix, followed by an intense degradation.

The ultrasound pretreatment was found to have a positive effect on the LAS degradation rate only in the digestion test performed with a high inoculum content $(\mathrm{F} / \mathrm{I}=0.3)$; in the other two tests the removal was more intense for untreated sludge, in particular for long chain homologues as C12 and C13.

\section{Conclusions}

The effect of the high-frequency ultrasound pretreatment was evaluated performing parallel batch digestion tests at different $\mathrm{F} / \mathrm{I}$ ratio $(0.3,0.6$ and 0.9$)$ with untreated and $200 \mathrm{kHz}$ pretreated sludge. Regarding specific biogas production, the positive effect of ultrasounds was evident, but the conversion rate of the sonicated sludge was affected by F/I, decreasing by increasing F/I. First order kinetic highlighted a decreasing trend of the hydrolysis rate by increasing F/I. Surfactants removal occurred always, but the effect of ultrasounds was significant only at $F / I=0.3$. Low $F / I$ resulted the ideal ratio improving both sludge anaerobic digestion and decontamination.

\section{Acknowledgements}

This work was supported by the ROUTES project funded from the European Union's Seventh Programme for research, technological development and demonstration under Grant agreement No. 265156.

\section{References}

APHA, 1998. Standard Methods for the Examination of Water and Wastewater, 20th ed. American Public Health Association, Washington, DC.

Angelidaki, I., Torang, L., Waul, C.M., Schmidt, J.E., 2004. Anaerobic bioprocessing of sewage sludge, focusing on degradation of linear alkylbenzene sulfonates (LAS). Water Sci. Technol. 49, 115-122.

Angelidaki, I., Alves, M., Bolzonella, D., Borzacconi, L., Campos, L., Guwy, A., Jenicek, P., Kalyuzhnui, S., van Lier, J., 2009. Defining the biomethane potential (BMP) of solid organic wastes and energy crops: a proposed protocol for batch assays. Water Sci. Technol. 59 (5), 927-934.

Berna, J.L., Ferrer, J., Moreno, A., Prats, D., Bevia, F.R., 1989. The fate of LAS in the environment. Tenside Surfactant Deterg. 26, 101-107.

Bolzonella, D., Pavan, P., Battistoni, P., Cecchi, F., 2005. Mesophilic anaerobic digestion of waste activated sludge: influence of the solid retention time in the wastewater treatment process. Process Biochem. $40, \quad 1453-1460$.

Bouchez, M., Blanchet, D., Vandecasteele, J.P., 1995. Substrate availability in phenanthrene biodegradation: transfer mechanism and influence on metabolism. Appl. Microbiol. Biotechnol. 43, 952-960.

Bougrier, C., Carrère, H., Delgènes, J.P., 2005. Solubilisation of waste-activated sludge by ultrasonic treatment. Chem. Eng. J. 106, 163-169.

Braguglia, C.M., Mininni, G., Tomei, M.C., Rolle, E., 2006. Effect of feed/inoculum ratio on anaerobic digestion of sonicated sludge. Water Sci. Technol. 54 (5), 78 84.

Braguglia, C.M., Gianico, A., Mininni, G., 2011. Laboratory-scale ultrasound pretreated digestion of sludge: heat and energy balance. Bioresour. Technol. $102,7567-7573$.

Braguglia, C.M., Gagliano, C., Rossetti, S., 2012. High frequency ultrasound pretreatment for sludge anaerobic digestion: effect on floc structure and microbial population. Bioresour. Technol. 110, 43-49.

Carlsson, M., Lagerkvist, A., Morgan-Sagastume, F., 2012. The effects of substrate pre-treatment on anaerobic digestion systems: a review. Waste Manag. 32 (9), 1634-1650.

CEN/TS 16189, Sludge, treated biowaste and soil-determination of linear alkylbenzene sulfonates (LAS) by high-performance liquid chromatography (HPLC) with fluorescence detection (FLD) or mass selective detection (MS), Final Draft, 2010.

Dubois, M., Gilles, K.A., Hamilton, J.K., Rebers, P.A., Smith, F., 1956. Colorimetric method for determination of sugars and related substances. Anal. Chem. 28, 350-356.

Engelhart, M., 2002. Anaerober Abbau Mechanish Desintegrierten Ueberschussschlammes. Institut für Siedlungswasserwirtschaft-Technische Universität Braunschweig, Heft, 68.

Gallipoli, A., Braguglia, C.M., 2012. High-frequency ultrasound treatment of sludge: combined effect of surfactants removal and floc disintegration. Ultrason. Sonochem. 19 (4), 864-871.

García, M.T. Campos, E., Ribosa, I., Latorre, A., Sánchez-Leal, J., 2005. Anaerobic digestion of linear alkyl benzene sulfonates: biodegradation kinetics and metabolite analysis. Chemosphere 60 (11), 1636-1643. 
Gianico, A., Braguglia, C.M., Mescia, D., Mininni, G., 2013. Ultrasonic and thermal pretreatments to enhance the anaerobic bioconversion of olive husks. Bioresour. Technol. 147, 623-626.

Khanal, S.K., Grewell, D., Sung, S., Van Leeuwen, J.H., 2007. Ultrasound applications in wastewater sludge pre-treatment: a review. Crit. Rev. Environ. Sci. Technol. 37, 277-313.

Liu, G., Zhang, R., El-Mashad, H.M., Dong, R., 2009. Effect of feed to inoculum ratios on biogas yields of food and green wastes. Bioresour. Technol. 100, 5103-5108.

Mogensen, A.S., Haagensen, F., Ahring, B.K., 2003. Anaerobic degradation of linear alkylbenzene sulfonate. Environ. Toxicol. Chem. 4, 706-711.

Neis, U., Nickel, K., Lundén, A., 2008. Improving anaerobic and aerobic degradation by ultrasonic disintegration of biomass. J. Environ. Sci. Health Part A - Toxic/ Hazard Subst. Environ. Eng. 43 (13), 1541-1545.

Neves, L., Oliveira, R., Alves, M.M., 2004. Influence of inoculum activity on the biomethanization of a kitchen waste under different waste/inoculum ratios. Process Biochem. 39, 2019-2024.

Novak, J.T., Sadler, M.E., Murthy, S.N., 2003. Mechanisms of floc destruction during anaerobic and aerobic digestion and the effect on conditioning and dewatering of biosolids. Water Res. 37, 3136-3144.

Pavlostathis, S.G., Gossett, J.M., 1986. A kinetic model for anaerobic digestion of biological sludge. Biotechnol. Bioeng. 28, 1519-1530.

Perez-Elvira, S.I., Fdz-Polanco, M., Plaza, F.I., Garrafòn, G., Fdz-Polanco, F., 2009. Ultrasounds pre-treatment for anaerobic digestion improvement. Water Sci. Technol. 60 (6), 1525-1532.

Pilli, S., Bhunia, P., Yan, S., LeBlanc, R.J., Tyagi, R.D., Surampalli, R.Y., 2011. Ultrasonic pretreatment of sludge: a review. Ultrason. Sonochem. 18, 1-18.

Prashanth, S., Kumar, P., Mehrotra, I., 2006. Anaerobic degradability: effect of particulate COD. J. Environ. Eng. ASCE 132 (4), 488-496.
Raposo, F., Borja, R., Martin Santos, M.A., Martin, A., de la Rubia, M.A., Rincon, B. 2009. Influence of inoculum-substrate ratio on the anaerobic digestion of sunflower oil cake in batch mode: process stability and kinetic evaluation. Chem. Eng. J. 149 (1-3), 70-77.

Shimizu, T., Kudo, K., Nasu, Y., 1993. Anaerobic waste activated sludge digestion-a bioconversion and kinetic model. Biotechnol. Bioeng. 41, 1082-1091.

Taylor, K.A.C.C., 1994. A modification of the phenol sulfuric-acid assay for tota carbohydrates giving more comparable absorbances. Appl. Biochem. Biotechnol. 53, 207-214.

Tiehm, A., Nickel, K., Zellhorn, M., Neis, U., 2001. Ultrasonic waste activated sludge disintegration for improving anaerobic stabilization. Water Res. 35, 2003-2009.

Tomei, M.C., Braguglia, C.M., Mininni, G, 2008. Anaerobic degradation kinetics of particulate organic matter in untreated and sonicated sewage sludge: role of the inoculum. Bioresour. Technol. 99 (14), 6119-6126.

Trably, E., Patureau, D., Delgenes, J.P., 2003. Enhancement of polycyclic aromatic hydrocarbons removal during anaerobic treatment of urban sludge. Water Sci. Technol. 48 (4), 53-60.

Vavilin, V.A., Rytov, S.V., Lokshina, L.Y., 1996. A description of hydrolysis kinetics in anaerobic degradation of particulate organic matter. Bioresour. Technol. 56 (23), 229-237.

Xie, R., Xing, Y., Ghani, Y.A., Ooi, K., Ng, S., 2007. Full-scale demonstration of an ultrasonic disintegration technology in enhancing anaerobic digestion of mixed primary and thickened secondary sewage sludge. J. Environ. Eng. Sci. 6, 533541.

Zhang, P., Chen, Y.G., Zhou, Q., 2010. Effect of surfactant on hydrolysis products accumulation and short-chain fatty acids (SCFA) production during mesophilic and thermophilic fermentation of waste activated sludge: kinetic studies. Bioresour. Technol. 101, 6902-6909. 